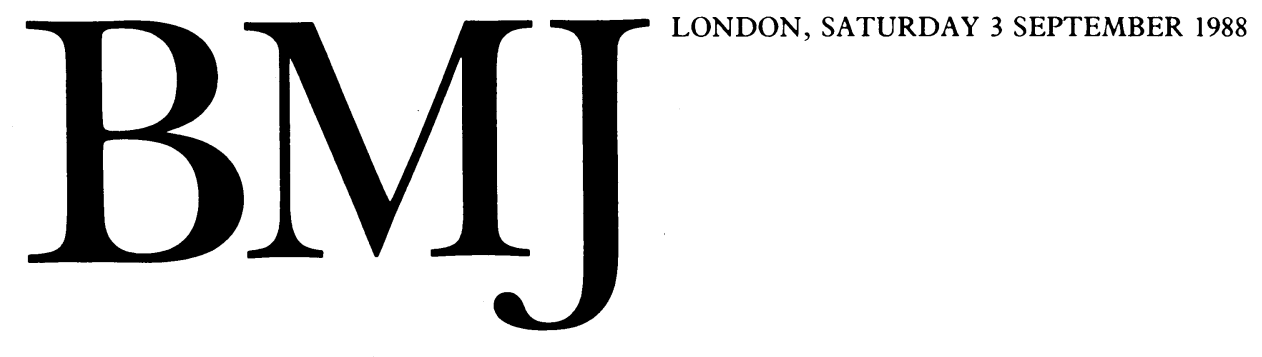

\title{
Holding back the tide of caesareans
}

\author{
Publishing recommendations is not enough to stop the rise
}

In England and Wales almost $15 \%$ of births are by caesarean section. In Canada the figure is nearly $20 \%$ and in the United States over $25 \%$. Even in The Netherlands, which has one of Europe's lowest rates for caesarean section, the rate is approaching double figures. Despite this wide variation among countries in the rate of caesarean birth there is remarkable consistency in its upward trend for the past 20 years. ' These sustained increases have generated widespread concern and attempts to stop the rise.

Few are left defending the current rates. ${ }^{2}$ Rather, most recent studies have shown the lack of relation between falling infant mortality and rising rates of caesarean section, ${ }^{3+}$ the seemingly arbitrary variability among and within countries in caesarean birth, ${ }^{156}$ the absence of evidence to support caesarean birth for many of its most common indications, ${ }^{7.9}$ or the many influences in addition to the welfare of mother and baby in the decision to perform a caesarean section. ${ }^{1011}$

Thus we see rising rates with falling justification and a generally agreed need for their reduction. Indeed, the 1987 president of the American College of Obstetricians and Gynecologists declared that the principal goal during his tenure was to reduce the unnecessarily high rate of caesarean section. ${ }^{12}$

The clinical indications mostly responsible for the rise are now well described. ${ }^{13-15}$ Where rates are low-for example, in Czechoslovakia and The Netherlands-the indications tend to be clear cut and specific. As the rate starts to rise into double figures it is driven by the liberal use of the poorly defined terms "failure to progress" and "fetal distress." Finally, as women who have had one child by caesarean section return for subsequent births the rate is pushed to $20 \%$ or above in those countries that uncritically apply Craigin's outdated dictum of "once a caesarean always a caesarean." Although in Britain the dictum has never been widely followed, in the United States and Canada the "diagnosis" of previous caesarean section now accounts for two thirds or more of the increase in the rate. Nine out of every 10 of such women receive a repeat caesarean section despite strong evidence contradicting such a policy.

Perhaps most important are the non-clinical variables that influence the rate upwards. ${ }^{13}$ One is the greater willingness of doctors to accept a high probability of a low level event-for example, infection and fever occurs in a fifth or more of women giving birth by caesarean section ${ }^{16}$ - rather than an extremely low probability of a traumatic event-for example, uterine rupture is $0.09 \%$ among women with a previous caesarean section who undertake labour. ${ }^{17}$ Also important are the overwhelming convenience of electively repeating a caesarean section; the difficulty in reversing any established trend in medical practice because of the natural desire to conform to peers' practice; the loss of clinical skills in vaginal delivery of the fetus presenting as a breech; fear of litigation (predominantly a North American affliction); the sometimes restrictive administrative rules and facilities of the hospital; and, finally, generally poor knowledge of research findings.

Targeted attempts to reduce the rate of caesarean births have nearly all focused solely on the poor knowledge of research findings. These exercises have synthesised the evidence, published recommendations on using caesarean section, and usually called for reduced rates. Although this is a potentially useful step, the long list of other causes of rising rates of caesarean section suggests that published recommendations are a necessary but not sufficient condition to change doctors' behaviour. Indeed, evaluations of a national consensus statement on caesarean section in the United States $^{18}$ showed that it may have improved doctors' knowledge but did little to reduce caesarean births. ${ }^{19-21}$ Similarly, in an exercise in Canada ${ }^{223}$ we are yet to see a change in the trend of the rate of caesarean section, at least in the 12 months after publication of the recommendations.

We are now attempting more aggressive measures to implement the recommendations. The consensus statement implementation project (CSIP) is a research study in randomly selected and assigned community hospitals. In one group we are capitalising on the informal networks of peer contact by identifying local "educational leaders" and giving them a workshop on the research evidence supporting the recommendations. We then send them back into their communities armed with materials based on the principles used in pharmaceutical marketing. In a second group of hospitals we are helping departments of obstetrics use the consensus statement for medical audit. The departments are given quarterly feedbacks on how well they are progressing towards compliance with the recommendations. Finally, in a control group we are merely posting the consensus statement to local doctors.

The interventions address at least some of the less appreciated causes of the increasing rate of caesarean section. In so far as they respect the contexts in which doctors actually practise medicine and in which babies are born we hope that the 
interventions might reduce caesarean sections moderately if not significantly. We will not know how well the project has worked or whether there will be some delayed impact of having merely published the recommendations until early in 1989. What is already clear is that without clearly targeted initiatives the multifaceted causes driving the rate of caesarean section upwards will influence doctors' behaviour far more than continued calls from researchers for a reduced rate.

JONATHAN LOMAS

Associate Professor in Clinical Epidemiology and Biostatistics and Associate Coordinator of the Centre for Health Economics and Policy Analysis,

Health Sciences Centre,

McMaster University,

Hamilton,

Ontario,

Canada L8N $3 Z 5$

The author receives personal support from the Ontario Ministry of Health, and the work is partly funded by NHRDP grant No 66063390-57 from Health and Welfare Canada.

1 Notzon FC, Placek PJ, Taffel SM. Comparisons of national cesarean section rates. $N$ Engl f Med 1987;316:386-9.

2 Feldman GB, Freiman JA. Prophylactic cesarean section at term? N Engl f Med 1985;312:1264-7.

3 Hemminki E. Obstetric practice in Finland, 1950-1980: changes in technology and its relation to health. Med Care 1983;21:1134-43.

4 Bodner B, Benjamin A, McLean FH, Usher RH. Has use of cesarean section reduced the risks of delivery in the breech presentation? Am $\mathcal{F}$ Obstet Gynecol 1986;154:244-50.
Bergsjo P, Schmidt E, Pusch D. Differences in the reported frequencies of some obstetrical interventions in Europe. Br f Obstet Gynaecol 1983;90:628-32.

6 Anderson GM, Lomas J. Explaining variations in cesarean section rates: patients, facilities, o policies? Can Med Assoc $\mathcal{7}$ 1985;132:253-9

Collea JV, Chein C, Quilligan EJ. The randomized management of term frank breech presentation a study of 208 cases. Am f Obstet Gynecol 1980;137:235-42.

Paul RH, Phelan JP, Yeh S. Trial of labor in the patient with a prior cesarean birth. Am $\mathcal{J}$ Obste Gynecol 1985;151:297-304

9 Banta HD, Thacker SB. Costs and benefits of electronic fetal monitoring: a review of the literature. Washington, DC: United States Department of Health, Education, and Welfare, 1979. (DHEW Publication No (PHS 79-3245)

10 Hurst M. Sumnev PS. Childbirth and social class: the case of a caesarean delivery. Soc Sci Med $1984: 18: 621-31$

1 Havnes de Regt R, Minkoff HL, Feldman J, Schwarz RH. Relation of private or clinic care to the cesarean birth rate. $N$ Engl f Med 1986;315:619-24

12 Anonymous. President's programme: can rise in c-section be reversed? American College of Obstetricians and (jvnecologists News Bulletin 1987;20:1(6).

13 Lomas J, Enkin M. Variations in operative delivery rates. In: Enkin MW, Keirse MJ, Chalmers I, eds. Effective care in pregnancy and childbirth. Oxford: Oxford University Press (in press).

14 Anderson GM, Lomas J. Determinants of the increasing cesarean birth rate: Ontario data, 1979 1982. N Engl f Med 1984;311:887-92.

15 Shiono PH, McNellis D, Rhoads GG. Reasons for the rising cesarean delivery rates: 1978-1984 Obstet Gynecol 1987;69:696-700

16 Gibbs RS. Infection after cesarean section. Clin Obstet Gynecol 1985;28:697-9.

17 Finley BE, Gibbs $\mathrm{CE}$. Emergent cesarean delivery in patients undergoing a trial of labor with a transverse lower-segment scar. Am f Obstet Gynecol 1986;155:936-9.

18 National Institutes of Child Health and Diseases Task Force on Cesarean Childbirth. Report. Bethesda, Maryland: National Institutes of Health, 1981. (DHHS Publication No (NIH) $82-2067$ ).

19 Gleicher $N$ Cesarean section rates in the United States. The short-term failure of the Nationat Consensus Development Conference in 1980. FAMA 1984;252:3273-6.

20 Shiono PH, Fielden JG, MCNellis D, Rhoads GG, Pearse WH. Recent trends in cesarean birth and trial of labor rates in the United States. JAMA 1987:257:494-7.

21 Kosecoff J, Kanouse DE, Rogers WH, McCloskey L, Monroe Winslow C, Brook RH. Effects of the National Institutes of Health Consensus Development Program on physician practice. AMA 1987;258:2708-13

22 Panel and Planning Committee of the National Consensus Conference on Aspects of Cesarean Birth. Indications for cesarean section: final statement of the panel of the National Consensu Conference on Aspects of Cesarean Birth. Can Med Assoc J 1986;134:1348-52.

23 Lomas J, Anderson G, Enkin M, Vayda E, Roberts R, MacKinnon B. The role of evidence in the consensus process: results from a Canadian consensus exercise. $7 A M A$ 1988;259:3001-5.

\section{Anyone for tetanus?}

\section{Boosters advised for adults on every decade birthday}

An active immunisation programme has meant that tetanus has virtually ceased to afflict children in Britain. In adults there are encouraging downward trends in incidence and death, but about 30-50 cases still occur each year-and between $10 \%$ and $60 \%$ of these patients die. Half the cases occur in patients over 65 , and more than half of these follow gardening injuries; the prognosis worsens with age. ${ }^{1.3}$ Rare events remain someone else's concern till they strike at home, and Bibby and Dixon's report on the low cover against the disease among their adult patients stems from a death in their own practice (p 598).

Bibby and Dixon have carried out a simple and probably widely reproducible survey of the records of 600 adults attending their surgery. Only $13 \%$ were certainly protected against tetanus. Even if the stringency of their judgments was relaxed to fit with the 10 year pattern of booster injections widely recommended on both sides of the Atlantic, around three quarters of their patients were still at risk. This figure is in line with estimates from elsewhere: Grabenstein et al reported that $53 \%$ of those over 60 reporting for influenza immunisation were inadequately protected against tetanus ${ }^{4}$; and Williams et al found that $40-80 \%$ were unprotected in their review. ${ }^{3}$

The theoretical work from which immunisation policies will evolve demands complicated mathematical projections. The standard recent work comes from Denmark, where Simonsen et al studied rates of loss of protection under different circumstances. 'They report that $28 \%$ of patients are unprotected 25-30 years after primary immunisation if no booster has been given. They believe that immunity lasts longer after revaccination than after primary vaccination. They find only one (doubtful) case of tetanus reported in a patient within five years after receiving primary protection but were not able to comment on whether revaccination on its own at injury guarantees cover. Recognising the risks of hyperimmunisation (neuropathy and anaphylaxis) with too frequent boosting, they advise primary immunisation in infancy, a boost at five years, a further boost at 25 years, and then boosts every 20 years.

This is where theory and practice become uncomfortable bedfellows. Patients' ability to remember their past medical histories is inexact over even short periods of time, and they are unlikely to recollect accurately the dates of injections received more than 10 years previously. The average patient changes doctor about once every 10 years, and the transfer of records between practices means that clinical and administrative information may be lost. It seems wise to prefer revaccination every 10 rather than every 20 years, and arranging this on the decade could add point to the growing fashion of celebrating 40th, 50th, and other similar anniversaries in style. For the patients currently attending the surgery whose immunity is uncertain I recommend a full course for any adult never before immunised (and that means anyone over 40 until proved otherwise) and a single opportunist injection for anyone previously covered but not boosted within 10 years. Once this has been achieved clean trauma need cause no anxiety and dirty wounds need a booster only if the last one was more than five years previously. For those with injuries whose previous immunity is unknown I advise toxoid for all wounds and human tetanus immune globulin as well for dirty ones.

Formulating a biologically appropriate policy is, however, not the only issue: problems in primary care also prevent immunisation of everybody. Firstly, the information overload 